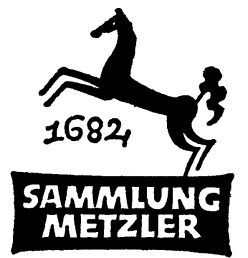

REALIEN ZUR LITERATUR ABT. D:

LITERATURGES CHICHTE 
KARL FEHR

\section{Conrad Ferdinand Meyer}

MCMLXXI

J. B. METZLERSCHE VERLAGSBUCHHANDLUNG STUTTGART 
M 102

ISBN 978-3-476-10102-0

ISBN 978-3-476-99009-9 (eBook)

DOI 10.1007/978-3-476-99009-9

(C) 1971 Springer-Verlag GmbH Deutschland

Ursprünglich erschienen bei J. B. Metzlersche Verlagsbuchhandlung und Carl Ernst Poeschel Verlag GmbH in Stuttgart 1971. 


\section{VORWORT}

Unter den drei großen Dichtern, die das geistige Bild der Schweiz in der Zeit $\mathrm{zw}$ wischen Goethes Tod und dem Beginn des zwanzigsten Jahrhunderts bestimmen, steht CoNRAD FERDINAND MEYER (1825-1898) zeitlich gesehen an dritter Stelle. Aber er war der erste Schweizer, der nur Dichter, und dies mit seiner ganzen Persönlichkeit, war. Das ist seine Größe, seine Grenze und zugleich seine Tragik. Jenes vielfältige politische, soziale, weltanschauliche Engagement, das die führenden Geister der Schweiz seit Albrecht von Haller und Heinrich Pestalozzi bestimmte und das Jeremias Gotthelf und Gottfried Keller zunächst die Feder in die Hand gedrückt hatte, war in diesem späten Abkömmling zürcherischer Bürgergeschlechter ein kaum spürbarer Anreiz. Die Motivation für das dichterische Tun ist viel tiefer in der psychischen Struktur und im eigenartigen Schicksal verlagert. Nicht daß die damalige Gegenwart keinen Anteil an seinem Werk hätte. Doch erscheinen die zeitgeschichtlichen Ereignisse nur in mehrfachen Brechungen im Oeuvre C. F. Meyers. Es wird auch zu zeigen sein, in welchem Maße die religiös-kirchliche und die allgemeine Gesellschaftsstruktur an seiner geistig-seelischen Entwicklung mitbestimmend geworden ist.

Ein aufrichtiger und herzlicher Dank für großzügige Hilfe ist an dieser Stelle abzutragen an die Steo-Stiftung in Zürich. Ohne ihre von Werner Weber so spontan vermittelte Unterstützung wäre dieses Werk nicht zustande gekommen.

Frauenfeld, im Mai 1971

KarL FeHR 


\section{INHALTSVERZEICHNIS}

I. HANDSChRIfTen, Vorab- UND ERSTDRUCK DER Werke, Briefe, Biographien . . . . . . . . . 1

1. Handschriften . . . . . . . . . . 1

2. Die Vorabdrucke in Zeitschriften . . . . . . . . . 4

3. Erstdrucke, Wissenschaftliche Ausgabe ...... 5

4. Briefe ............... 9

5. Biographien und größere Werke über CFM .... 9

II. Das Leben vor der Dichterzeit (1825-1865) . . . . 11

1. Herkunft . . . . . . . . . . . . 11

2. Jugendzeit und Entwicklungskrise . . . . . . . . . 19

3. Entspannung . . . . . . . . . . . 29

4. Erwachendes Dichtertum . . . . . . . . 36

III. Der Aufstieg (1865-1875) . . . . . . . . . . . . 39

1. "Huttens letzte Tage* . . . . . . . . . . 42

2. "Engelberg" . . . . . . . . . . 45

3. $\gg$ Das Amulett« . . . . . . . . . . . . . 47

4. "Jürg Jenatsch . . . . . . . . . . . . . 50

5. Ehe und eigenes Heim. Rehabilitation . . . . . . 55

IV. ReIfezeIt (1875-1887) . . . . . . . . . . . . . . . 59

1. Der Schuß von der Kanzel« ......... 59

2. "Der Heilige* . . . . . . . . . . . . 61

3. Plautus im Nonnenkloster « . . . . . . . . . 66

4. "Gustav Adolfs Page« . . . . . . . . . . . . . . 68

5. Die Gedichte . . . . . . . . . . . 70

6. "Das Leiden eines Knaben« . . . . . . . . . . . 82

7. "Die Hochzeit des Mönchs« . . . . . . . . . . 85

8. "Die Richterin« . . . . . . . . . . . . . . . . . 89

9. Die Versuchung des Pescara «. . . . . . . . . . . 94

V. Das Alter (1888-1898) . . . . . . . . . . . . . . 99

1. Das Jahr der Krisis . . . . . . . . . . . . . 99

2. "Angela Borgia . . . . . . . . . . . 101

3. Dämmerung und Ende . . . . . . . . . 106

VI. Conrad Ferdinand Meyers religiöse Welt . . . . . . 110

VII. Zur WirkungSGeschichte. . . . . . . . . . . . . . 111

VIII. Die Conrad Ferdinand Meyer-Forschung . . . . . 112

REGISTER . . . . . . . . . . . . . . 118 


\section{AbKürzUngen}

\begin{tabular}{|c|c|}
\hline Br. & Brief(e) \\
\hline Briefe I, II & "Briefe CFMs«, hrsg. v. Adolf Frey. 2 Bde. 1908 \\
\hline CFM & Conrad Ferdinand Meyer \\
\hline DD & >Deutsche Dichtung (Zeitschrift), hrsg. v. K. E. Franzos \\
\hline $\mathrm{dHC}$ & $\begin{array}{l}\text { Robert d'Harcourt: CFM. La crise } 1852-1856 . \\
\text { Paris } 1913\end{array}$ \\
\hline dHCFM & Ders.: CFM. Sa vie, son oeuvre. Paris 1913 \\
\hline$>\mathrm{DR}$ く & 'Deutsche Rundschau<, hrsg. v. J. Rodenberg \\
\hline GRM & Germanisch-Romanische Monatsschrift \\
\hline HBLS & "Historisch-biographisches Lexikon der Schweiz « \\
\hline Hs., hs. & Handschrift, handschriftlich \\
\hline $\mathrm{Jb}$. & Jahrbuch \\
\hline Ms. & Manuskript \\
\hline$>N Z Z$ & >Neue Zürcher Zeitung \\
\hline s. v. & sub voce: s. das Schlagwort des betr. Nachschlagewerkes \\
\hline W $1-15$ & $\begin{array}{l}\text { CFM: Sämtl. Werke. Histor.-krit. Ausgabe in } 15 \text { Bden. } \\
1958 \text { ff., s. S. } 8 \text { f. }\end{array}$ \\
\hline & Zeitschrift für dt. Bildung \\
\hline
\end{tabular}

